\title{
Back to the same place of holidays. An analysis of European tourists' preferences towards cultural tourism
}

\author{
Rui Amaral \\ Interdisciplinary Centre for History, Cultures and Societies (CIDEHUS) \\ University of Évora, Portugal \\ E-mail: ramaral@uevora.pt \\ $\&$ \\ Jaime Serra \\ Interdisciplinary Centre for History, Cultures and Societies (CIDEHUS) \\ University of Évora, Portugal \\ E-mail: jserra@uevora.pt
}

\section{Introduction}

Cultural tourism remains one of European tourists' main preference for travelling inside Europe (Kozak, 2002; Chaldler \& Costello, 2012). Travel has long been associated with cultural standards and levels, because a visitor who is motivated to explore, discover and learn about the attractions of a country or region exert an incalculable personal, social and professional investment. Although several studies have been conducted revisit intentions to sun and sand destinations (among others, Correia \& Zins, 2015). Thus, limited focus has been given to investigating return reasons based on cultural tourism preferences (Kastenholz et al, 2013).

This study aims to identify the preferences of Europeans in their demand for cultural tourism in terms of revisit the previous place of holidays. Previous studies revealed that tourist preferences are associated with destination attributes, past visits and intention to revisit (Woodside \& Lysonski, 1989, Decrop \& Snelders, 2005; Li \& Hudson, 2016). The attributes that explain the preferences of Europeans when intending to revisit the same place of holidays for cultural reasons will be identified. Findings are expected to provide European National Tourism Organisations and practitioners an amount of rich insights concerning the identification of return reasons towards cultural tourism preferences.

\section{Literature Review}

Tourist preferences is a concept related to consumer behaviour, and has been studied by different social sciences (Slovic, 1995). Preferences are considered tourist strategies and have many factors to describe motivations and processes of choice of product, attractions, destinations and revisit intentions (T.-K. Hsu et al, 2009; Tosun et al, 2015). These factors have the potential to influence the choices of the tourist, which grants the supply stakeholders a better and more competitive 